Check for updates

Cite this: Mater. Adv., 2022, 3, 1609

Received 15th November 2021, Accepted 15th December 2021

DOI: 10.1039/d1ma01077h

rsc.li/materials-advances

\title{
Facile room-temperature fabrication of a silver-platinum nanocoral catalyst towards hydrogen evolution and methanol electro-oxidation $\uparrow$
}

\begin{abstract}
Hau Quoc Pham (D) ab and Tai Thien Huynh (D) *c
With rising environmental problems, hydrogen produced from electrolyzing water has emerged as the most sustainable and clean energy source to replace fossil fuels in a variety of applications. Although platinum (Pt) is the most efficient catalyst towards the hydrogen evolution reaction (HER), its high cost is a large limitation. Herein, we report a simple self-growth-assisted reduction route for fabricating a coral-like dendritic AgPt alloy nanocatalyst on a carbon support to lower Pt utilization and enhance the electrocatalytic performance. Due to its unique morphological features and alloy nature, the AgPt nanocoral (NCs)/C catalyst with 50 at\% Ag shows excellent HER performance in acidic electrolyte with an extremely low overpotential of $16.61 \mathrm{mV}$ at $10 \mathrm{~mA} \mathrm{~cm}{ }^{-2}$ and a small Tafel slope of $19.05 \mathrm{mV} \mathrm{dec}^{-1}$, which are improved compared to those of a carbon-supported Pt (E-TEK) catalyst. In addition, the AgPt NCs/C catalyst exhibits enhanced reaction kinetics and superior CO-poisoning resistance for the methanol oxidation process. This study not only describes the design of a cost-effective HER catalyst but also provides a robust catalyst for energy conversion technologies.
\end{abstract}

\section{Introduction}

Due to serious environmental issues related to fossil fuel consumption, hydrogen production from the electrolysis of water has been considered to be one of the most sustainable and economic-efficient energy-generation technologies owing to its advantages of sufficient water sources and unharmful emissions. ${ }^{1,2}$ Electrocatalysts play an important role in boosting the electrochemical reaction rate by minimizing the overpotential and promoting the reaction kinetics during the HER; therefore, the Pt catalyst is widely used owing to its fast kinetics and low overpotential. ${ }^{1,3}$ The natural scarcity and high cost of $\mathrm{Pt}$, however, are major limitations for its particular implementation in the HER. ${ }^{4-6}$ A great number of studies have been performed to fabricate Pt-free catalysts as an approach to reduce the cost of the HER catalyst. For example, Li et al. ${ }^{3}$ introduced a H-CoP@RGO catalyst that exhibited catalytic performance for the HER with $190 \mathrm{mV}$ overpotential at $10 \mathrm{~mA} \mathrm{~cm}{ }^{-2}$ in an acidic environment. Sahu et al. ${ }^{7}$ reported

\footnotetext{
${ }^{a}$ Future Materials \& Devices Lab., Institute of Fundamental and Applied Sciences, Duy Tan University, Ho Chi Minh City, 700000, Vietnam

${ }^{b}$ The Faculty of Environmental and Chemical Engineering, Duy Tan University, Da Nang, 550000, Vietnam

${ }^{c}$ Ho Chi Minh City University of Technology (HCMUT), Ho Chi Minh City, 700000, Vietnam.E-mail: httai@hcmunre.edu.vn

$\dagger$ Electronic supplementary information (ESI) available. See DOI: 10.1039/d1ma01077h
}

MOF-D CoSe ${ }_{2}$ for the HER with an overpotential of $195 \mathrm{mV}$ at the current density of $10 \mathrm{~mA} \mathrm{~cm} \mathrm{~cm}^{-2}$ and a Tafel slope of $43 \mathrm{mV} \mathrm{dec}^{-1}$. Nonetheless, low catalytic activity is still a large obstacle to their application; therefore, designing and developing cost-effective and active catalysts is necessary.

In the current era, introducing transition metals into the Pt catalyst is considered a robust strategy to boost the electrocatalytic performance and reduce the utilization of Pt by the bifunctional mechanism and the electronic effect. ${ }^{1,8,9}$ Even though the integration of Pt with inexpensive metals such as $\mathrm{Ni}, \mathrm{Fe}$, and Co exhibits an advantage in economic benefit, these nanoalloys are still susceptible to oxidation, resulting in their catalytic instability in long-term operating conditions. ${ }^{10-12}$ Because its price is equivalent to that of cobalt and less than $2 \%$ that of platinum, silver $(\mathrm{Ag})$ has emerged as a favorable alloy component for Pt to obtain excellent electrocatalytic stability owing to its high oxidation resistance. ${ }^{11}$ In addition, the incorporation of $\mathrm{Ag}$ not only modifies the electronic structure but also increases the activation of Pt surface-active sites, which is attributable to the effective removal of adsorbed intermediate species on the Pt surface at a low potential by the formation of $\mathrm{Ag}(\mathrm{OH})_{\mathrm{ads} .}{ }^{4,13,14}$ For instance, Huang et al. ${ }^{15}$ reported PtAg alloy NPs embedded in polyaniline that exhibited higher HER activity than Pt NPs with a $41 \mathrm{mV}$ overpotential at $10 \mathrm{~mA} \mathrm{~cm}{ }^{-2}$. Nonetheless, zero-dimensional (0D) Pt-based NPs were normally unstable under harsh electrochemical reaction 
conditions by the aggregation and Oswald ripening process. ${ }^{14,16,17}$ Adjusting the morphology and structure of Ptbased catalysts has been considered to be a powerful way to enhance the catalytic activity and stability. Song et al. ${ }^{18}$ prepared a coral-like PdAg catalyst by a polyol route that displayed superior CO-tolerance and great catalytic stability for glycerol oxidation; however, the use of polyvinylpyrrolidone (PVP) as a capping agent for the formation of the coral-like nanostructure can be a limitation because it potentially interferes with the catalyst activities. ${ }^{11,19}$

Although extensive reports have presented the high catalytic activity of the bimetallic PtAg alloy nanocatalyst for the HER and MOR, either complex processes, ${ }^{4,20}$ high temperature, ${ }^{14}$ or surfactant agents ${ }^{15,21}$ have been required for the fabrication of PtAg alloys. In this work, we introduce a coral-like dendritic AgPt nanoalloy on a carbon support by adjusting the nucleation and growth of $\mathrm{Pt}$ and $\mathrm{Ag}$ in an aqueous solution at room temperature. With 50 at\% $\mathrm{Ag}$, the as-made $\mathrm{AgPt}$ NCs/C catalyst showed great electrocatalytic performance for both the HER and MOR in an acidic electrolyte. In terms of the HER, the asobtained catalyst exhibited an extremely small overpotential $(16.61 \mathrm{mV})$ at $10 \mathrm{~mA} \mathrm{~cm}^{-2}$ and a low Tafel slope (19.05 $\mathrm{mV} \mathrm{dec}^{-1}$ ) in comparison with the Pt NPs/C (E-TEK) catalyst. In addition, the $\mathrm{AgPt} \mathrm{NCs} / \mathrm{C}$ catalyst demonstrated a negative onset potential $\left(0.32 \mathrm{~V}_{\mathrm{RHE}}\right)$, large current density (22.88 $\mathrm{mA} \mathrm{cm}^{-2}$ ), and impressive CO-poisoning resistance toward the MOR. The ADT results also indicated superior catalytic stability of the AgPt NCs/C catalyst for both the HER and MOR. Apart from the synergistic effect of $\mathrm{Ag}$, the unique morphological features with more active sites also contributed significantly to enhancing the catalytic performance of the asmade AgPt NCs/C catalyst.

\section{Results and discussion}

The morphology and particle size of the as-made catalyst were recorded by TEM and HR-TEM analysis. Fig. 1a and b depict a typical coral-like dendritic structure with nanometer size $(\sim 3 \mathrm{~nm}$ in diameter and a length of $\sim 10 \mathrm{~nm})$. Also, the HRTEM images in Fig. 1c and d indicate that the inter-planar spacing distances of the AgPt NCs/C catalyst were about $0.23 \mathrm{~nm}$, attributed to the indexed (111) facets of the facecubic-center (fcc) AgPt nanoalloy. ${ }^{4,5}$ To investigate the elemental distribution of the AgPt NCs, energy-dispersive X-ray spectroscopy (EDX) mapping was performed during STEM. Fig. $1 \mathrm{e}-\mathrm{g}$ shows the presence of silver and platinum with uniform distribution in the as-obtained catalysts, suggesting the formation of the bimetallic AgPt nanocoral catalyst. In this work, the coral-like AgPt nanoalloy was anchored on the carbon surface by a simple reduction process at room temperature using $\mathrm{AgNO}_{3}$ and $\mathrm{H}_{2} \mathrm{PtCl}_{6}$ as metal precursors and $\mathrm{HCOOH}$ as a reducing agent, as illustrated in Fig. $1 \mathrm{~h}$. For the aqueous formic acid-reducing route, the formate anions produced by the formic acid dehydration were favorable to the development of Pt along the (111) orientation because of the extremely slow reduction
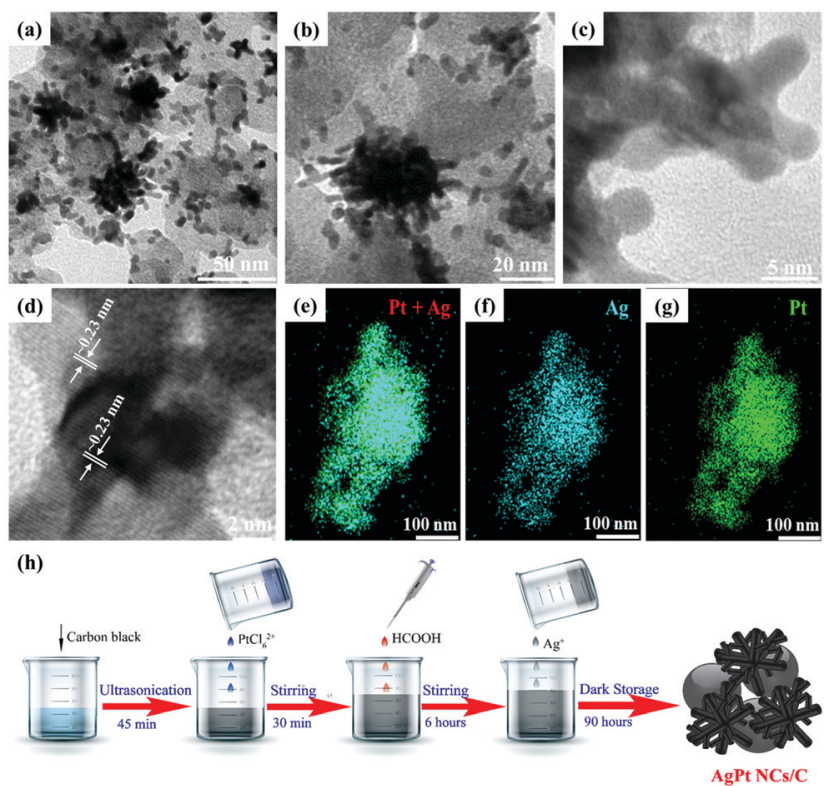

Fig. 1 ( $a$ and b) TEM images, (c and d) HR-TEM images, (e-g) EDX mapping, and (h) schematic of the preparation process of AgPt NCs/C.

reaction and the lowest energy principle. ${ }^{22-24}$ At low concentrations, the Pt seeds were firstly formed by formic acid due to the slow chemical reduction of Pt ions. ${ }^{25}$ These seeds can be autocatalytic for the Pt reduction reaction when they obtain a fixed size (about 500 atoms). ${ }^{25,26}$ Since the standard reduction potential of $\mathrm{Ag}$ ions $\left(\mathrm{Ag}^{+}\right)$is higher than that of $\mathrm{Pt}$ ions $\left(\mathrm{Pt}^{4+}\right.$ and $\mathrm{Pt}^{2+}$ ), the reduction reaction kinetics of $\mathrm{Pt}$ is slower than that of $\mathrm{Ag}$ under the same aqueous conditions. Therefore, the Pt ions must first be reduced to generate crystal seeds for the formation of both Pt and $\mathrm{Ag}$ in a particular direction; as a result, the $\mathrm{Ag}$ precursor is added to the whole system after the controlled Pt reduction duration. ${ }^{11}$ In brief, the Pt seeds were first formed and deposited onto the surface of carbon black by the reduction of $\mathrm{PtCl}_{6}{ }^{2-}$ by formic acid, which acted as sites for the absorption and reduction of $\mathrm{Ag}^{+}$ions to form clustered particles. Under the extremely slow reduction rate at room temperature, the (111) direction was preferential according to the lowest-energy principle, resulting in the formation of the coral-like dendritic AgPt catalyst.

The XRD analysis was performed in the $2 \theta$ range from $20^{\circ}$ to $80^{\circ}$ to investigate the structure information of the AgPt NCs/C catalyst. As can be observed in Fig. 2a, the XRD pattern of the as-made catalyst showed three typical diffraction peaks at the $2 \theta$ angles of around $38.82^{\circ}, 44.79^{\circ}$, and $66.68^{\circ}$ of the (111), (200), and (220) facets of the fcc AgPt nanoalloy. ${ }^{27,28}$ Another peak was considered at a $2 \theta$ angle of about $25^{\circ}$, featuring the (002) facet of the hexagonal structure of carbon; this demonstrates that the bimetallic AgPt NCs were successfully anchored onto the carbon surface. ${ }^{4,29}$ In addition, the diffraction peaks of the as-obtained catalysts lay between those of standard $\mathrm{Ag}$ (JCPDS 04-0783) and Pt (JCPDS 04-0802), which were assigned to the lattice distortion by the different atom sizes of $\mathrm{Ag}$ and $\mathrm{Pt}$, further confirming the formation of AgPt nanocrystals. ${ }^{27,30}$ 


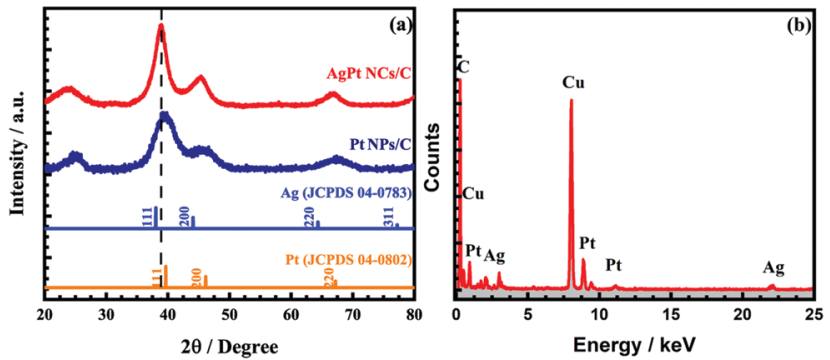

Fig. 2 (a) $X$-ray diffraction patterns in the $2 \theta$ range of $20^{\circ}$ to $80^{\circ}$ at a step size of $0.02^{\circ}$, and (b) energy-dispersive $X$-ray spectrum of the as-obtained AgPt NCs/C electrocatalyst.

The coherent length $\left(D_{(k h l)}\right)$ and lattice space $\left(d_{(h k l)}\right)$ of the AgPt NCs/C catalyst were calculated by Debye-Scherrer's formula and Bragg's law, respectively. As listed in Table S1 (ESI $\dagger$ ), the lattice space values of the AgPt NCs/C and Pt NPs/C catalysts were analogous at elevated order facets, suggesting that the investigated catalysts were developed based on metallic fcc Pt crystal. Additionally, the AgPt NCs/C catalyst showed a lattice expansion of $0.04 \AA$ in both the (111) and (200) facets compared to those of the Pt NPs/C catalyst, implying the favorable local alloying of $\mathrm{Ag}$ in these facets; this is appropriately expressed by the increase of the intensity ratio between the (111) facet and other crystal facets $\left(\mathrm{H}_{(111)} / \mathrm{H}_{(200)}\right.$ and $\left.\mathrm{H}_{(111)} / \mathrm{H}_{(220)}\right)$. ${ }^{31}$ Furthermore, the conformation of the crystal structure of the catalyst was further certified by the difference of the $D_{(h k l)}$. In the case of the Pt NPs/C (E-TEK) catalyst, the $D_{(111)}, D_{(200)}$, and $D_{(220)}$ values were $2.16 \mathrm{~nm}, 1.89 \mathrm{~nm}$, and $2.11 \mathrm{~nm}$, respectively, showing the unclear discrepancy of the crystallinity; this was further evidenced by the intensity ratio of the facets. ${ }^{31}$ Meanwhile, the AgPt NCs/C catalyst displayed favorable crystal development along the (111) facet by the largest $D_{(111)}$ among all crystal facets and the highest intensity proportion (7.50) of the crystal facet in the longitude axis (i.e. (111)) and the corresponding lateral facets (i.e. (220)), which agreed generally with the observation from the HR-TEM images. Additionally, the atomic $\mathrm{Ag}$ : Pt ratio was close to $1: 1$ by energy-dispersive X-ray spectroscopy, as shown in Fig. 2b. These results suggested the formation of the AgPt nanoalloy on the carbon surface via a simple reduction process.

The surface composition of the as-obtained nanocatalyst was investigated by the XPS analysis. The high-resolution spectrum of Pt $4 \mathrm{f}$ in Fig. 3a was deconstructed into two pairs of peaks; the strong pair at $70.40 \mathrm{eV}\left(\mathrm{Pt}_{4 \mathrm{f}_{7 / 2}}\right)$ and $73.72 \mathrm{eV}$ $\left(\mathrm{Pt} 4 \mathrm{f}_{5 / 2}\right)$ was attributed to the zerovalent state $\left(\mathrm{Pt}^{0}\right)$, whilst another weak couple was observed at $71.46 \mathrm{eV}\left(\mathrm{Pt}_{4 \mathrm{f}_{7 / 2}}\right)$ and $75.11 \mathrm{eV}$ ( $\mathrm{Pt} 4 \mathrm{f}_{5 / 2}$ ), ascribed to the ionic $\mathrm{Pt}^{2+}$ species. The presence of the $\mathrm{Pt}^{2+}$ states in the as-obtained AgPt NCs/C catalysts was attributable to the oxidized surficial Pt in the air or the residual precursors. ${ }^{9,14}$ The content of $\mathrm{Pt}^{0}$ was calculated as $71.86 \%$ by the peak area ratio of all split peaks of $\mathrm{Pt}^{0}$ and $\mathrm{Pt}^{2+}$, indicating the domination of the zerovalent $\mathrm{Pt}^{0}$ state. ${ }^{14}$ In terms of $\mathrm{Ag}$, the peak pair was considered at $367.94 \mathrm{eV}\left(\mathrm{Ag} 3 \mathrm{~d}_{5 / 2}\right)$ and $373.99 \mathrm{eV}\left(\mathrm{Ag} 3 \mathrm{~d}_{3 / 2}\right)$, attributed to the zerovalent state $\left(\mathrm{Ag}^{0}\right)$
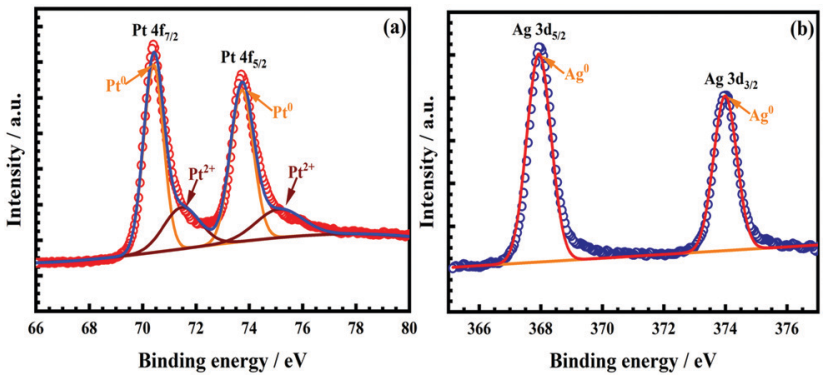

Fig. 3 High-resolution spectra of (a) $\mathrm{Pt} 4 \mathrm{f}$ and (b) $\mathrm{Ag} 3 \mathrm{~d}$ in the $\mathrm{AgPt}$ $\mathrm{NCs} / \mathrm{C}$.

in the as-prepared AgPt NCs/C catalysts, as shown in Fig. 3b. More importantly, the binding energy of the $\mathrm{Pt} 4 \mathrm{f}$ orbitals in the AgPt NCs/C catalyst showed a negative shift compared to those of the Pt NPs/C catalyst, ${ }^{8}$ demonstrating the electronic donation from $\mathrm{Ag}$ to Pt owing to their electronegativity difference (Pt of 2.28 and $\mathrm{Ag}$ of 1.93) ${ }^{14,32}$ This electron transfer resulted in a d-band center downshift of Pt, benefiting the removal of oxygen-containing species from the catalyst surface because of the decreased adsorption strength, thereby improving the catalytic performance. ${ }^{9,33}$ In addition, the binding energy of $\mathrm{Ag}$ displayed a adverse trend, with increases of the binding energy from 367.67 to $367.94 \mathrm{eV}$ for $\mathrm{Ag}^{0} 3 \mathrm{~d}_{5 / 2}$ and from 373.12 to $373.99 \mathrm{eV}$ for $\mathrm{Ag}^{0} 3 \mathrm{~d}_{7 / 2}$ in comparison with the pure Ag metal, ${ }^{34,35}$ further confirming the electron transfer from $\mathrm{Ag}$ to Pt.

The electrocatalytic activity of the as-obtained AgPt NCs/C catalyst was examed by cyclic voltammetry (CV) tests. As illustrated in Fig. 4a, the CV curves of the AgPt NCs/C and Pt NPs/C (E-TEK) catalysts exhibited typical voltammetric features of Pt, with the observed peaks in the potential range of 0.0-0.2 $\mathrm{V}_{\mathrm{RHE}}$ corresponding to the hydrogen adsorption and desorption regions. Meanwhile, the peaks at $1.0 \mathrm{~V}_{\mathrm{RHE}}$ in the forward scan and $0.8 \mathrm{~V}_{\mathrm{RHE}}$ in the backward scan were attributed to the oxidation and reduction of $\mathrm{Pt}$, respectively. The electrochemical surface areas (ECSAs) of the AgPt NCs/C and Pt NPs/C catalysts were $81.36 \mathrm{~m}^{2} \mathrm{~g}_{\text {Metal }}{ }^{-1}$ and $70.83 \mathrm{~m}^{2} \mathrm{mg}_{\text {Metal }}{ }^{-1}$, suggesting that the as-made AgPt NCs/C catalyst contained more active sites and was more accessible for the electroactive species; this was assigned to the unique coral-like dendritic nanostructures. ${ }^{36,37}$ To investigate the HER performance of the AgPt NCs/C catalyst, linear sweep voltammetry (LSV) was carried out. Fig. 4b demonstrates that the AgPt NCs/C catalyst exhibited an onset potential of $4.78 \mathrm{mV}$, which was shifted positively by about $1.72 \mathrm{mV}$ compared to the Pt NPs/C (E-TEK) catalyst $(6.51 \mathrm{mV})$. In terms of the HER, the current density at $10 \mathrm{~mA} \mathrm{~cm}{ }^{-2}$ was similar to that of a solar-to-hydrogen device to obtain about $12 \%$ efficiency, which is normally used as a key factor to assess the HER activity of catalysts. ${ }^{38,39}$ The inset of Fig. $4 \mathrm{~b}$ illustrates that the overpotential at the current density of $10 \mathrm{~mA} \mathrm{~cm}{ }^{-2}$ of the AgPt $\mathrm{NCs} / \mathrm{C}$ catalyst is $16.61 \mathrm{mV}$, which is $4.69 \mathrm{mV}$ better than that of the C-supported Pt (NPs) catalyst $(21.30 \mathrm{mV})$, suggesting improved catalytic activity of the AgPt NCs/C catalyst for the HER in an acidic environment. 



Fig. 4 (a) CV curves at a $25 \mathrm{mV} \mathrm{s}^{-1}$ scan rate; (b) LSV curves at a $5 \mathrm{mV} \mathrm{s}^{-1}$ scan rate (inset: overpotentials at $10 \mathrm{~mA} \mathrm{~cm}{ }^{-2}$ of the catalysts). (c) Tafel plots; (d) overpotentials at $10 \mathrm{~mA} \mathrm{~cm} \mathrm{~cm}^{-2}$ and Tafel slope values; and (e) comparison of the overpotentials at $10 \mathrm{~mA} \mathrm{~cm}^{-2}$ and Tafel slope values of the catalysts with those of other recently reported HER catalysts in $\mathrm{N}_{2}$-saturated $0.5 \mathrm{M} \mathrm{H}_{2} \mathrm{SO}_{4}$ electrolyte

Furthermore, the Tafel slope was calculated to assess the HER kinetics of the catalysts, as shown in Fig. 4c and $d$. The as-prepared AgPt NCs/C catalyst had a low Tafel slope (19.05 $\mathrm{mV} \mathrm{dec}^{-1}$ ), which was smaller than that of the C-supported Pt (NPs) catalyst (21.37 $\mathrm{mV} \mathrm{dec}^{-1}$ ), demonstrating the high HER activity of the AgPt NCs/C catalyst because the HER rate increased greatly as the overpotential increased. These results indicated that this AgPt NCs/C catalyst could drastically improve the HER catalytic activity of $\mathrm{Pt}$ and decrease the Pt loading, thereby reducing the cost for practical applications. In acidic medium, the HER was carried out according to three pathways, including the Volmer reaction: $\mathrm{H}_{2} \mathrm{O}+\mathrm{M}+\mathrm{e}^{-} \Leftrightarrow \mathrm{M}-\mathrm{H}^{*}+\mathrm{OH}^{-}$; the Heyrovsky reaction: $\mathrm{M}-\mathrm{H}^{*}+\mathrm{H}_{2} \mathrm{O}+\mathrm{e}^{-} \Leftrightarrow \mathrm{M}+\mathrm{OH}^{-}+\mathrm{H}_{2} ;$ and the Tafel reaction: $2 \mathrm{M}-\mathrm{H}^{*} \Leftrightarrow \mathrm{M}+\mathrm{H}_{2}$, where $\mathrm{M}$ is the active site and $\mathrm{H}_{\text {ads }}$ denotes the hydrogen atom adsorbed. ${ }^{40,41}$ The Tafel slope values of the as-obtained AgPt NCs/C and Pt NPs/C catalysts were similar and close to $30 \mathrm{mV} \mathrm{dec}{ }^{-1}$, demonstrating that the HER kinetics of the catalysts was determined by the Tafel step and according to the Volmer-Tafel mechanism. ${ }^{42}$ Fig. $4 \mathrm{e}$ and Table S2 (ESI $\dagger$ ) show the high HER activity of the AgPt NCs/C catalyst, which was better than that of Pt NPs/C and recently reported Pt-based catalysts in an acidic environment. In
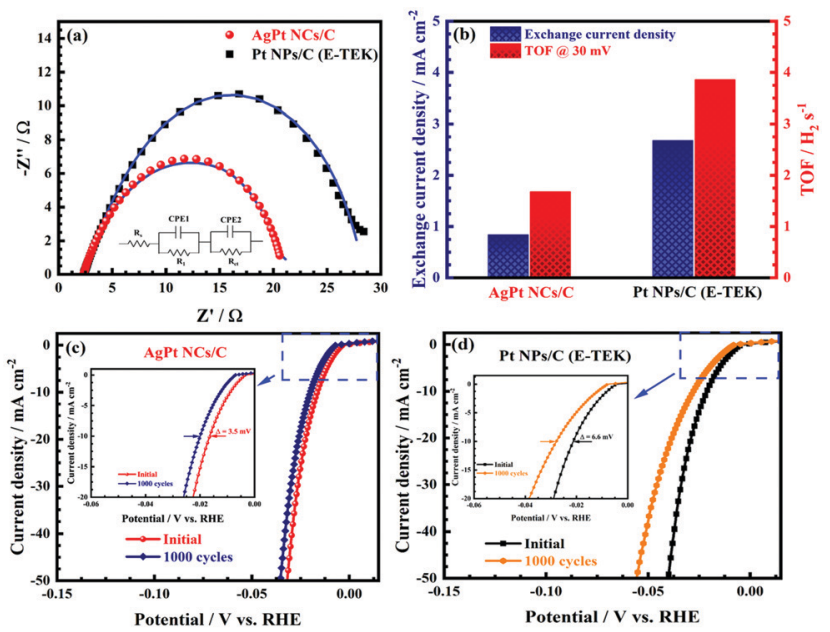

Fig. 5 (a) Nyquist plots at an amplitude of $5 \mathrm{mV}$ in the frequency range from 0.1 to $10^{5} \mathrm{~Hz}$; (b) exchange current density and turnover frequency; and (c and d) LSV curves at a $5 \mathrm{mV} \mathrm{s}^{-1}$ scan rate in the first cycle and 1000 cycles of the AgPt NCs/C and Pt NPs/C catalyst in $\mathrm{N}_{2}$-saturated $0.5 \mathrm{M}$ $\mathrm{H}_{2} \mathrm{SO}_{4}$ aqueous solution.

addition to the large ECSA value, the enhancement of the AgPt NCs/C catalyst was assigned to the electronic structure modification of the Pt, which accelerated the HER kinetics by decreasing the adsorption strength of $\mathrm{H}_{\mathrm{ads}}$ on the catalyst surface and facilitated the combination of adjacent $\mathrm{H}_{\mathrm{ads}}$ and the rapid release of $\mathrm{H}_{2}{ }^{33,43}$

To further study the electron transfer kinetics during the HER process of the as-obtained AgPt NCs/C catalysts, electrochemical impedance spectroscopy (EIS) was used. The equivalent circuit diagram of the EIS data in the inset of Fig. 5a exhibit the solution resistance $R_{\mathrm{s}}, R_{1} \| \mathrm{CPE} 1$ and $R_{\mathrm{ct}}|| \mathrm{CPE} 2$ elements, with $R_{1}$ and $R_{\mathrm{ct}}$ attributed to the electrode surface and electrocatalytic kinetics, respectively. ${ }^{44}$ According to the Nyquist plots in Fig. 5 , the $R_{\text {ct }}$ of the as-made AgPt NCs/C catalyst was $18.26 \Omega$, which was lower than that of Pt NPs/C (26.08 $\Omega$ ), suggesting a faster electron transfer and preferential kinetics during the HER process on the AgPt NCs/C catalyst. In addition, the excellent HER activity of the as-prepared catalysts was further confirmed by the exchange current density $\left(j_{0}\right)$, which was extrapolated from the Tafel plots. ${ }^{33,45}$ The $j_{0}$ of the AgPt NCs/ C catalyst was $2.68 \mathrm{~mA} \mathrm{~cm}^{-2}$, which was 3.19 -fold greater than that of the Pt NPs/C catalyst $\left(0.84 \mathrm{~mA} \mathrm{~cm}^{-2}\right)$, demonstrating the high intrinsic activity for the HER of the AgPt NCs/C catalyst (Fig. 5b). Furthermore, the TOF value of $\mathrm{AgPt} \mathrm{NCs} / \mathrm{C}$ was $3.86 \mathrm{H}_{2} \mathrm{~s}^{-1}$, which was superior to that of the commercial Pt NPs/C $\left(1.68 \mathrm{H}_{2} \mathrm{~s}^{-1}\right)$, suggesting the high intrinsical HER activity of the as-prepared catalyst. ${ }^{33,46}$ Additionally, ADT was performed to record the long-term stability of the HER catalysts, which plays an important role in practical applications. After 1000 cycling tests, the as-prepared AgPt NCs/C catalyst exhibited good catalytic stability, with an overpotential shift at $10 \mathrm{~mA}$ $\mathrm{cm}^{-2}$ of $3.5 \mathrm{mV}$; this was about half the value of $6.6 \mathrm{mV}$ for carbon-supported Pt (NPs) catalyst (Fig. 5c and d), indicating the stability improvement of the AgPt NCs/C catalyst. Table 1 
Table 1 A summary of the electrocatalytic performance of the HER catalyst in acidic media

\begin{tabular}{|c|c|c|c|c|c|}
\hline Catalyst & $\begin{array}{l}\text { Overpotential at } \\
10 \mathrm{~mA} \mathrm{~cm}{ }^{-2} \mathrm{mV}\end{array}$ & $\begin{array}{l}\text { Tafel slope } \\
\text { mV dec }^{-1}\end{array}$ & $\begin{array}{l}j_{0} \mathrm{~mA} \\
\mathrm{~cm}^{-2}\end{array}$ & $R_{\mathrm{ct}} \Omega$ & $\begin{array}{l}\text { TOF } \\
\mathrm{H}_{2} \mathrm{~s}^{-1}\end{array}$ \\
\hline $\mathrm{AgPt} \mathrm{NCs} / \mathrm{C}$ & 16.61 & 19.05 & 2.68 & 18.26 & 3.86 \\
\hline Pt NPs/C (E-TEK) & 21.30 & 21.37 & 0.84 & 26.08 & 1.68 \\
\hline
\end{tabular}

summarizes the HER performance of the AgPt NCs/C catalyst in acidic electrolytes.

The catalytic performance of the as-made $\mathrm{AgPt} \mathrm{NCs} / \mathrm{C}$ catalyst was further investigated for the methanol electrooxidation process by $\mathrm{CV}$ tests. Fig. 6a depicts that the $\mathrm{CV}$ curves exhibited the typical two peaks for the MOR of Pt-based catalysts, including the positive-going scan peak, attributed to the methanol oxidation, and another negative-going scan peak, which was attributed to the oxidation process of the intermediate species produced during the MOR. As expected, the MOR peak of AgPt NCs/C was observed at $0.82 \mathrm{~V}_{\mathrm{RHE}}$; this was shifted negatively by $30 \mathrm{mV}$ in comparison with that of the commercial catalyst $\left(0.85 \mathrm{~V}_{\mathrm{RHE}}\right)$, suggesting that the methanol oxidation process was easier and faster on the AgPt NCs/C catalyst. In addition, the $I_{\mathrm{f}} / I_{\mathrm{b}}$ ratio of the AgPt NCs/C catalyst was calculated to be 1.47 , which was improved compared to that of the commercial catalyst (0.85), indicating the better CO-like tolerance of the AgPt NCs/C catalyst. Although the Pt loading was reduced significantly, the AgPt NCs/C catalysts still showed a mass activity of $175.25 \mathrm{~mA} \mathrm{mg} \mathrm{Metal}^{-1}$ and specific activity of $0.35 \mathrm{~mA} \mathrm{~cm}^{-2}$, which was better than those of the C-supported Pt (NPs) catalyst (161.02 mA mg ${ }_{\text {Metal }}^{-1}$ for mass activity and $0.23 \mathrm{~mA} \mathrm{~cm}{ }^{-2}$ for a specific activity), as depicted in Fig. $6 \mathrm{~b}$ and Table S3 (ESI $\dagger$ ). The high catalytic activity of the AgPt NCs/C catalyst could be interpreted as due to (i) the unique coral-like dendritic nanostructure of the AgPt NCs, which supplies more active sites and smooth routes for rapid diffusion and transfer
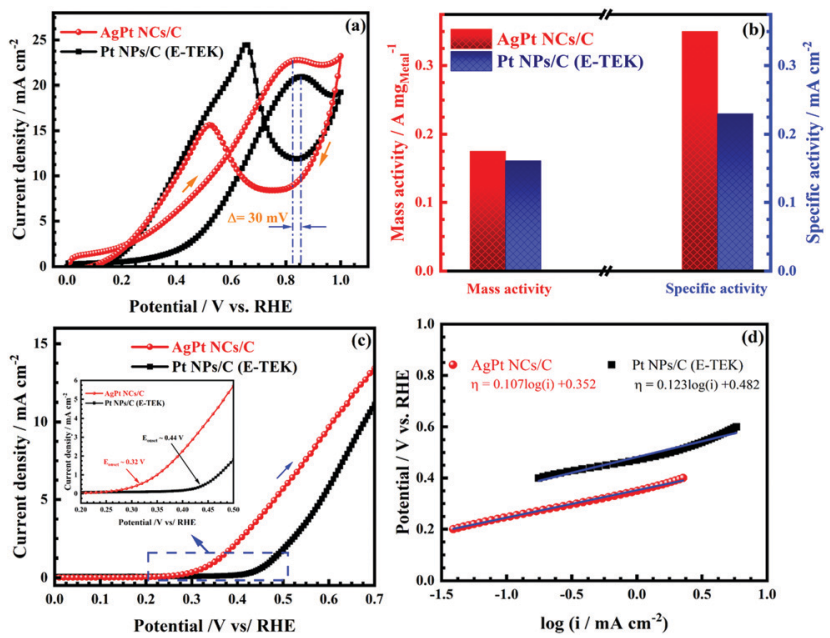

Fig. 6 (a) CV curves at a $25 \mathrm{mV} \mathrm{s}^{-1}$ scan rate; (b) mass activity and specific activity; (c) LSV curves at a $1 \mathrm{mV} \mathrm{s}^{-1}$ scan rate; and (d) Tafel plots of the asmade AgPt NCs/C and Pt NPs/C (E-TEK) catalysts in $\mathrm{N}_{2}$-saturated $0.5 \mathrm{M}$ $\mathrm{H}_{2} \mathrm{SO}_{4}+1.0 \mathrm{M} \mathrm{CH}{ }_{3} \mathrm{OH}$ aqueous solution. of the reactants and products, promoting the oxidation process of small organic molecules; ${ }^{47,48}$ (ii) the incorporation of $\mathrm{Ag}$ into the Pt catalyst, which enhanced the activation of the surfaceactive sites of the Pt. ${ }^{4,49}$

The LSV test was performed to further record the electrocatalytic activity of the as-obtained AgPt NCs/C catalyst. As can be seen in Fig. 6c, the AgPt NCs/C electrocatalyst exhibited a MOR onset potential of $0.32 \mathrm{~V}_{\mathrm{RHE}}$, which was a much more negative potential than that of $0.44 \mathrm{~V}_{\mathrm{RHE}}$ for Pt NPs/C. In addition, the Tafel slope of the AgPt NCs/C catalyst was $107.08 \mathrm{mV} \mathrm{dec}^{-1}$, which was smaller than that of the commercial catalyst (123.36 mV dec${ }^{-1}$ ), indicating the enhancement of the MOR kinetics of the AgPt NCs/C catalyst in acidic media (Fig. 6d). By the Tafel equation, the kinetic parameters of the investigated MOR catalysts were also calculated and are listed in Table 2. The exchange current density $\left(j_{0}\right)$ of the as-prepared AgPt NCs/C catalyst was $5.13 \times 10^{-4} \mathrm{~mA} \mathrm{~cm}{ }^{-2}$, which was $4.23-$ fold greater than that of the C-supported Pt (NPs) catalyst $\left(1.21 \times 10^{-4} \mathrm{~mA} \mathrm{~cm}^{-2}\right)$. The high $j_{0}$ of the AgPt NCs/C catalyst implied a faster electrode reaction, contributing significantly to enhancing the MOR activity. ${ }^{50}$ Also, the charge transfer coefficients $(\alpha)$ of the as-obtained AgPt NCs/C and Pt NPs/C catalysts were 0.56 and 0.48 , respectively, demonstrating the improvement of the electron transfer during the MOR process on the AgPt NCs/C catalyst. In brief, the above results suggested high MOR activity of the AgPt NCs/C catalyst.

The CO-tolerant ability of catalysts plays an important role in boosting their MOR activity; therefore, the CO-tolerance of the AgPt NCs/C catalyst was examed by the CO-stripping test. Fig. 7a depicts the CO-stripping curves of the MOR catalysts, which indicate the impressive CO-tolerance of the as-obtained $\mathrm{AgPt} \mathrm{NCs} / \mathrm{C}$ catalyst. For example, the AgPt NCs/C catalyst exhibited a $\mathrm{CO}_{\mathrm{ads}}$ onset potential of $0.63 \mathrm{~V}_{\mathrm{RHE}}$, which was $70 \mathrm{mV}$ more negative in comparison with that of the commercial catalyst $\left(0.70 \mathrm{~V}_{\mathrm{RHE}}\right)$, suggesting that the $\mathrm{CO}_{\mathrm{ads}}$ oxidation occurred more readily on the AgPt NCs/C catalyst. The $\mathrm{CO}_{\text {ads }}$ oxidation peak of the AgPt NCs/C catalyst was observed at $0.75 \mathrm{~V}_{\mathrm{RHE}}$, which was negatively shifted in comparison with the Pt NPs/C (0.78 $\left.\mathrm{V}_{\mathrm{RHE}}\right)$, demonstrating the superior $\mathrm{CO}$ antipoisoning resistance of the AgPt NCs/C catalyst. Additionally, the chronoamperometry (CA) test was used to further evaluate the catalytic activity and possible CO-like poisoning under continuous operating conditions. As illustrated in Fig. 7b, the initial current density of the AgPt NCs/C catalyst was higher than that of Pt NPs/C, indicating the improved MOR activity of the AgPt NCs/C catalyst. Before achieving a pseudo-steady state,

Table 2 A summary of the MOR performance of the investigated catalysts in acidic media

\begin{tabular}{|c|c|c|c|c|}
\hline Catalyst & $\begin{array}{l}\text { Onset } \\
\text { potential } \\
\mathrm{V}_{\mathrm{RHE}}\end{array}$ & $\begin{array}{l}\text { Tafel slope } \\
\mathrm{mV} \mathrm{dec}^{-1}\end{array}$ & $\begin{array}{l}\text { Exchange } \\
\text { current } \\
\text { density } \\
\mathrm{mA} \mathrm{cm}^{-2}\end{array}$ & $\begin{array}{l}\text { Charge transfer } \\
\text { coefficient }\end{array}$ \\
\hline $\mathrm{AgPt}$ & 0.32 & 107.08 & $5.13 \times 10^{-4}$ & 0.56 \\
\hline Pt NPs/C (E-TEK) & 0.44 & 123.36 & $1.21 \times 10^{-4}$ & 0.48 \\
\hline
\end{tabular}



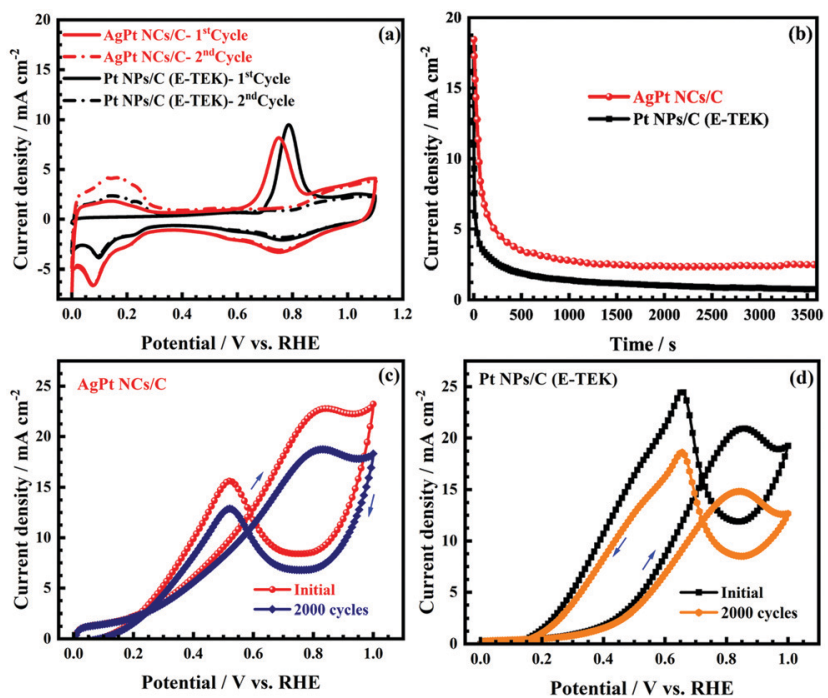

Fig. 7 (a) CO-stripping in $0.5 \mathrm{M} \mathrm{H}_{2} \mathrm{SO}_{4}$ at a $25 \mathrm{mV} \mathrm{s}^{-1}$ scan rate; (b) $\mathrm{CA}$ curves at the fixed potential of $0.7 \mathrm{~V}_{\mathrm{RHE}}$ for $3600 \mathrm{~s}$; and (c and d) 2000cycling ADT of the different electrocatalysts in $\mathrm{N}_{2}$-saturated $0.5 \mathrm{M} \mathrm{H}_{2} \mathrm{SO}_{4}$ $+1.0 \mathrm{M} \mathrm{CH}_{3} \mathrm{OH}$ aqueous solution.

deterioration of the current density was detected at the first stage; this was unavoidable because of the methanol concentration difference caused by diffusion on the anode surface and the formation of the Pt oxide. ${ }^{28,51}$ The current density at the pseudo-steady state of the AgPt NCs/C catalyst was higher than that of Pt NPs/C, confirming the impressive MOR stability of the AgPt NCs/C catalyst. Also, the TEM and HR-TEM images in Fig. S1 (ESI $\dagger$ ) indicate that the morphology of the AgPt NCs/C catalyst was almost unchanged after the CA test, indicating the high catalytic stability of the as-made catalyst in long-term duration. Furthermore, the high MOR stability of the as-made catalyst was further exhibited by ADT, as shown in Fig. 7c, d, and Table S4 (ESI $\dagger$ ). After the 2000-cycling test, the MOR current density of the AgPt NCs/C catalyst decayed by around $17.52 \%$, against a significant decrease of $28.74 \%$ for the Pt NPs/C catalyst. The improvement of the AgPt NCs/C catalyst was assigned to the electronic transfer from $\mathrm{Ag}$ to Pt, which was proven by the XPS results, causing the enriched electron density of Pt and weakening the bond strength with the lone electron pair of CO and/or other intermediate species, thereby reducing the binding and poisoning effect. $^{14,52-54}$ Additionally, the incorporation of $\mathrm{Ag}$ into the $\mathrm{Pt}$ nanocatalyst can effectively remove the adsorbed carbonaceous intermediates on the surface of the $\mathrm{Pt}$ by the formation of $\mathrm{OH}_{\mathrm{ads}}$ on the neighboring $\mathrm{Ag}$ surface from water dissociation at a lower potential than $\mathrm{Pt}^{4,13,14}$ Briefly, the above properties resulted in less accumulation and easier oxidation of CO-like species during the electrochemical oxidation process, leading to improvement of the CO-like tolerance of the AgPt NCs/C catalyst. Meanwhile, the high intrinsic stability of the coral-like nanostructures under electrochemical conditions induced less aggregation and Ostwald ripening compared to the 0D counterparts, ${ }^{18,48}$ resulting in enhancement of the catalytic stability of the AgPt NCs/C catalyst.

These experimental results indicated that the coral-like dendritic AgPt catalyst exhibited high HER and MOR performance in an acidic environment, although its Pt loading was reduced significantly compared to that of the commercial catalyst. The enhancement of the AgPt NCs/C catalyst was assigned to the following reasons: (i) the unique coral-like dendritic nanostructure can not only supply more active sites and greater accessibility to the reactants and products but also promote the charge transfer, which can greatly facilitate the HER and MOR process and thus improve the catalytic performance of the AgPt NCs/C catalyst. ${ }^{4,36,37}$ Also, the coral-like nanostructures had high intrinsic durability under electrochemical conditions compared to the 0D Pt NPs, thereby enhancing the catalytic stability of the AgPt NCs/C catalyst. $^{18,48}$ (ii) Alloying of $\mathrm{Ag}$ with Pt decreases the d-band center of the Pt by the electronic effect, weakening the affinity of the surface intermediates and/or products to the exposed $\mathrm{Pt}$ active sites and eventually endowing the AgPt NCs/C catalyst with enhanced catalytic activity. ${ }^{14,34}$ In addition, the incorporation of $\mathrm{Ag}$ into the Pt-based catalyst can effectively oxidize the $\mathrm{CO}_{\mathrm{ads}}$ through the unique ability to produce hydroxyl species from water dissociation at low potential (i.e., bifunctional effect), ${ }^{13,55}$ contributing to the enhanced CO-tolerant ability of the AgPt NCs/C catalyst.

\section{Conclusions}

In brief, a coral-like dendritic AgPt nanocatalyst was successfully fabricated by a facile room-temperature fabrication process without using any structure-directing agent. The unique morphological features endowed the catalyst with geometric and surface electronic merits to enhance the reaction kinetics towards the HER and MOR in an acidic environment. Due to the synergistic and electronic effect between $\mathrm{Ag}$ and $\mathrm{Pt}$, improved performance of the AgPt NCs/C catalyst with a low overpotential at the current density of $10 \mathrm{~mA} \mathrm{~cm}^{-2}$ and a small Tafel slope compared to those of the commercial catalyst for the HER were obtained. In addition, the as-made catalyst demonstrated high HER stability, with an overpotential deterioration of $3.5 \mathrm{mV}$ against a large decay of $6.6 \mathrm{mV}$ for the commercial Pt NPs/C catalyst. Furthermore, the as-prepared AgPt NCs/C catalyst displayed a high current density and catalytic stability as well as superior CO-tolerant ability towards the MOR. This work could provide cost-efficient and robust catalysts for the HER and MOR, which plays an important role in clean energy generation and conversion technologies.

\section{Experimental}

In a typical fabrication of the AgPt NCs/C catalyst, ${ }^{11} 25 \mathrm{mg}$ of carbon black was ultrasonicated in $50 \mathrm{~mL}$ of distilled water (DW) for $45 \mathrm{~min}$ to generate a homogeneous suspension. Afterward, $1 \mathrm{~mL}$ of $\mathrm{H}_{2} \mathrm{PtCl}_{6} 0.01 \mathrm{M}$ in $20 \mathrm{~mL}$ of $\mathrm{DW}$ was gradually dropped into the obtained suspension; then, $10 \mathrm{~mL}$ $\mathrm{HCOOH}$ was added. After $6 \mathrm{~h}, 2 \mathrm{~mL}$ of $\mathrm{AgNO}_{3} 0.05 \mathrm{M}$ in $20 \mathrm{~mL}$ DW was added under stirring for $30 \mathrm{~min}$; then, the resulting mixture was stored in the dark at room temperature for 
90 hours to finish the reaction. The formed product was rinsed repeatedly with DW and absolute ethanol, followed by drying at $80{ }^{\circ} \mathrm{C}$. Detailed information of the material properties and electrochemical tests are demonstrated in the ESI. $\dagger$

\section{Author contributions}

Hau Quoc Pham: conceptualization, writing-original draft preparation, and software. Tai Thien Huynh: methodology, investigation, data curation, reviewing and editing, and supervision.

\section{Conflicts of interest}

There are no conflicts to declare.

\section{Acknowledgements}

Hau Quoc Pham was funded by Vingroup Joint Stock Company and supported by the Domestic Master/PhD Scholarship Programme of Vingroup Innovation Foundation (VINIF), Vingroup Big Data Institute (VINBIGDATA), VINIF.2020.TS.108.

\section{Notes and references}

1 F. Guo, Z. Zou, Z. Zhang, T. Zeng, Y. Tan, R. Chen, W. Wu, N. Cheng and X. Sun, J. Mater. Chem. A, 2021, 9(9), 5468-5474.

2 L. Y. Zhang, Z. L. Zhao and C. M. Li, Nano Energy, 2015, 11, 71-77.

3 Z. Li, D. Wu, Y. Ouyang, H. Wu, M. Jiang, F. Wang and L. Y. Zhang, Appl. Surf. Sci., 2020, 506, 144975.

4 H. Xu, B. Yan, S. Li, J. Wang, C. Wang, J. Guo and Y. Du, ACS Sustainable Chem. Eng., 2018, 6(1), 609-617.

5 Q. Liu, Y.-M. He, X. Weng, A.-J. Wang, P.-X. Yuan, K.-M. Fang and J.-J. Feng, J. Colloid Interface Sci., 2018, 513, 455.

6 Z. L. Zhao, L. Y. Zhang, S. J. Bao and C. M. Li, Appl. Catal., B, 2015, 174-175, 361-366.

7 N. Sahu, J. K. Das and J. N. Behera, Sustainable Energy Fuels, 2021, 5(19), 4992-5000.

8 T. T. Huynh, N. N. Dang and H. Q. Pham, Catal. Sci. Technol., 2021, 11(4), 1571-1579.

9 H. Q. Pham and T. T. Huynh, ACS Appl. Nano Mater., 2021, 4(5), 4983-4993.

10 R. Borup, J. Meyers, B. Pivovar, Y. S. Kim, R. Mukundan, N. Garland, D. Myers, M. Wilson, F. Garzon, D. Wood, P. Zelenay, K. More, K. Stroh, T. Zawodzinski, J. Boncella, J. E. McGrath, M. Inaba, K. Miyatake, M. Hori, K. Ota, Z. Ogumi, S. Miyata, A. Nishikata, Z. Siroma, Y. Uchimoto, K. Yasuda, K.-I. Kimijima and N. Iwashita, Chem. Rev., 2007, 107(10), 3904-3951.

11 E. Fidiani, G. Thirunavukkarasu, Y. Li, Y.-L. Chiu and S. Du, J. Mater. Chem. A, 2020, 8(23), 11874-11883.

12 F. Maillard, L. Dubau, J. Durst, M. Chatenet, J. André and E. Rossinot, Electrochem. Commun., 2010, 12(9), 1161-1164.
13 G.-T. Fu, B.-Y. Xia, R.-G. Ma, Y. Chen, Y.-W. Tang and J.-M. Lee, Nano Energy, 2015, 12, 824-832.

14 X. Fu, C. Wan, A. Zhang, Z. Zhao, H. Huyan, X. Pan, S. Du, X. Duan and Y. Huang, Nano Res., 2020, 13(5), 1472-1478.

15 M. Huang, H. Zhang, S. Yin, X. Zhang and J. Wang, ACS Appl. Nano Mater., 2020, 3(4), 3760-3766.

16 H. Q. Pham, T. T. Huynh, A. T. N. Mai, T. M. Ngo, L. G. Bach and V. T. T. Ho, Sci. Rep., 2019, 9(1), 14791.

17 Y. Gong, X. Liu, Y. Gong, D. Wu, B. Xu, L. Bi, L. Y. Zhang and X. S. Zhao, J. Colloid Interface Sci., 2018, 530, 189-195.

18 P. Song, J.-J. Feng, F.-Y. Guo and A.-J. Wang, J. Mater. Chem. A, 2015, 3(31), 15920-15926.

19 G. Zhang, Z. Yang, W. Zhang, H. Hu, C. Wang, C. Huang and Y. Wang, Nanoscale, 2016, 8(5), 3075-3084.

20 Y. Kim, H. Kim and W. B. Kim, PtAg nanotubes for electrooxidation of ethylene glycol and glycerol in alkaline media, Electrochem. Commun., 2014, 46, 36-39.

21 F. Gao, H. Xu, Y. Zhang, J. Wang, C. Wang and Y. Du, Int. J. Hydrogen Energy, 2018, 43(20), 9644-9651.

22 C.-W. Liu, Y.-C. Wei, C.-C. Liu and K.-W. Wang, J. Mater. Chem., 2012, 22(11), 4641-4644.

23 S. Sun, F. Jaouen and J.-P. Dodelet, Adv. Mater., 2008, 20(20), 3900-3904.

24 S. H. Sun, D. Q. Yang, D. Villers, G. X. Zhang, E. Sacher and J. P. Dodelet, Adv. Mater., 2008, 20(3), 571-574.

25 Y. Song, Y. Yang, C. J. Medforth, E. Pereira, A. K. Singh, H. Xu, Y. Jiang, C. J. Brinker, F. van Swol and J. A. Shelnutt, J. Am. Chem. Soc., 2004, 126(2), 635-645.

26 E. Greenbaum, J. Phys. Chem., 1988, 92(16), 4571-4574.

27 Z. Peng, H. You and H. Yang, Adv. Funct. Mater., 2010, 20(21), 3734.

28 X. Cao, N. Wang, Y. Han, C. Gao, Y. Xu, M. Li and Y. Shao, Nano Energy, 2015, 12, 105-114.

29 Y. Zhao, L. Yang, S. Chen, X. Wang, Y. Ma, Q. Wu, Y. Jiang, W. Qian and Z. Hu, J. Am. Chem. Soc., 2013, 135(4), 1201-1204.

30 X. Weng, Q. Liu, A.-J. Wang, J. Yuan and J.-J. Feng, J. Colloid Interface Sci., 2017, 494, 15-21.

31 T.-H. Huang, D. Bhalothia, S. Dai, C. Yan, K.-W. Wang and T.-Y. Chen, Sustainable Energy Fuels, 2021, 5(11), 2960-2971.

32 J.-J. Feng, X.-X. Lin, L.-X. Chen, M.-T. Liu, J. Yuan and A.-J. Wang, J. Colloid Interface Sci., 2017, 498, 22-30.

33 X. Zhang, S. Wang, C. Wu, H. Li, Y. Cao, S. Li and H. Xia, J. Mater. Chem. A, 2020, 8(45), 23906-23918.

34 A. B. Yousaf, M. Imran, A. Zeb, T. Wen, X. Xie, Y.-F. Jiang, C.-Z. Yuan and A.-W. Xu, Electrochim. Acta, 2016, 197, 117-125.

35 S.-S. Chen, L.-J. Nan, J.-J. Feng, L. Zhang, K.-M. Fang, X. Luo and A.-J. Wang, Int. J. Hydrogen Energy, 2018, 43(12), 6096-6106.

36 H. Huang, L. Ma, C. S. Tiwary, Q. Jiang, K. Yin, W. Zhou and P. M. Ajayan, Small, 2017, 13(10), 1603013.

37 J.-P. Zhong, C. Hou, L. Li, M. Waqas, Y.-J. Fan, X.-C. Shen, W. Chen, L.-Y. Wan, H.-G. Liao and S.-G. Sun, J. Catal., 2020, 381, 275.

38 X. Chia, N. A. A. Sutrisnoh and M. Pumera, ACS Appl. Mater. Interfaces, 2018, 10(10), 8702-8711. 
39 M. Wei, L. Huang, S. Huang, Z. Chen, D. Lyu, X. Zhang, S. Wang, Z. Q. Tian and P. K. Shen, J. Catal., 2020, 381, 385-394.

40 J. Hu, C. Fang, X. Jiang, D. Zhang and Z. Cui, Inorg. Chem. Front., 2020, 7(22), 4377-4386.

41 L. Li, S. Wang, L. Xiong, B. Wang, G. Yang and S. Yang, J. Mater. Chem. A, 2019, 7(20), 12800-12807.

42 Y. Zhang, L. Liu, C. Sun, Y. Du, Y. Zhou and Q. Xie, J. Alloys Compd., 2021, 888, 161564.

43 X. Wang, L. Bai, J. Lu, X. Zhang, D. Liu, H. Yang, J. Wang, P. K. Chu, S. Ramakrishna and X.-F. Yu, Angew. Chem., Int. Ed., 2019, 58(52), 19060-19066.

44 B. Jiang, H. Yuan, Q. Dang, T. Wang, T. Pang, Y. Cheng, K. Wu, X. Wu and M. Shao, Int. J. Hydrogen Energy, 2019, 44(59), 31121.

45 C. Wei, R. R. Rao, J. Peng, B. Huang, I. E. L. Stephens, M. Risch, Z. J. Xu and Y. Shao-Horn, Adv. Mater., 2019, 31(31), 1806296.

46 X. Bao, Y. Gong, Y. Chen, H. Zhang, Z. Wang, S. Mao, L. Xie, Z. Jiang and Y. Wang, J. Mater. Chem. A, 2019, 7(25), 15364-15370.

47 L.-Y. Jiang, A.-J. Wang, X.-S. Li, J. Yuan and J.-J. Feng, ChemElectroChem, 2017, 4(11), 2909-2914.
48 X. Jiang, Y. Liu, J. Wang, Y. Wang, Y. Xiong, Q. Liu, N. Li, J. Zhou, G. Fu, D. Sun and Y. Tang, Nano Res., 2019, 12(2), 323-329.

49 X. ong, C. Tan, J. Liu, J. Yang, X.-J. Wu, Z. Fan, Z. Luo, J. Chen, X. Zhang, B. Chen and H. Zhang, J. Am. Chem. Soc., 2015, 137(4), 1444-1447.

50 S. Lee, H. J. Kim, S. M. Choi, M. H. Seo and W. B. Kim, Appl. Catal., A, 2012, 429-430, 39-47.

51 C. Fang, J. Zhao, G. Zhao, L. Kuai and B. Geng, Nanoscale, 2016, 8(32), 14971-14978.

52 L. Y. Zhang, F. Wang, S. Wang, H. Huang, X. Meng, Y. Ouyang, W. Yuan, C. X. Guo and C. M. Li, Adv. Funct. Mater., 2020, 30, 2003933.

53 Y. Zhang, F. Gao, P. Song, J. Wang, J. Guo, Y. Shiraishi and Y. Du, ACS Sustainable Chem. Eng., 2019, 7(3), 3176-3184.

54 Y. Ouyang, H. Cao, H. Wu, D. Wu, F. Wang, X. Fan, W. Yuan, M. He, L. Y. Zhang and C. M. Li, Appl. Catal., B, 2020, 265, 118606.

55 J.-J. Lv, J.-X. Feng, S.-S. Li, Y.-Y. Wang, A.-J. Wang, Q.-L. Zhang, J.-R. Chen and J.-J. Feng, Electrochim. Acta, 2014, 133, 407-413. 